\title{
Acute Respiratory Distress Syndrome in the Elderly
}

\author{
Ganshyam Jagathkar@
}

\begin{abstract}
Acute respiratory distress syndrome (ARDS) is a commonly encountered complex syndrome of varied etiology and outcomes. The elderly population is at a high risk of developing severe ARDS with poor outcomes. The age-related changes in the immune system, structural and functional modifications of the respiratory system, and the frailty with a decrease in the physiological reserve of organ systems place them precariously for poor outcomes. However, does age alone influence the outcomes or is it the associated comorbidities that determine mortality in the elderly is not clearly known.

Keywords: Acute respiratory distress syndrome, Elderly people, Outcomes.

Indian Journal of Critical Care Medicine (2021): 10.5005/jp-journals-10071-23877
\end{abstract}

Acute respiratory distress syndrome (ARDS) is a complex, heterogeneous syndrome associated with a high mortality in general and particularly in the elderly population. ${ }^{1,2}$ Though the precise mechanisms underlying the increased severity and incidence of ARDS in these patients are poorly understood, the process of aging per se may put them at such a risk. Age is associated with poor outcomes in critically ill patients and is a key component of various scoring systems-acute physiology and chronic health evaluation and simplified acute physiology score-which help in prognosticating patients though they lack specificity. There are no validated scoring systems specific to ARDS patients. The 9-point APPS scoring tool, which also included age, was prospectively evaluated by Villar et al. $^{3}$ and found to have poor outcomes in patients with a higher score. Studies have also found age to be an independent predictor of mortality in ARDS patients. ${ }^{4,5}$

Outcomes in ARDS can be influenced by multiple factorsimmune function, structural and functional reserve of pulmonary system, changes within the airway, and the vasculature. ${ }^{6}$ Aging-induced decline in immune function is well documented. Activation of immune cells leading to the release of inflammatory cytokines is the key mechanism in the pathophysiology of ARDS and immunosenescence can have a significant impact in the aged subpopulation. Adding to these are the comorbidities commonly encountered in the elderly, making them vulnerable to organ failures and associated poor outcomes. Inherently, these factors create a bias that the elderly population does badly when diagnosed with ARDS and put on invasive ventilation. And in a pandemic situation where resources are stretched to the limit, clinicians are often faced with the question of whether age should be one of the deciding factors to offer invasive ventilation to the elderly.

Host response is a key factor impacting outcomes of patients in ARDS. Age-related changes in the immune function predispose these patients to poorer outcomes. It would be intuitive, that aging-related proinflammatory responses, dysregulated activation of inflammatory cells, higher incidence of endothelial dysfunction would be the primary factor influencing mortality in this group. An interesting study by Schouten and group, ${ }^{7}$ who looked at the host response in elderly patients with ARDS, found that the biomarkers of inflammation and endothelial dysfunction were significantly lower in the elderly compared to the younger, hinting that the host response associated with aging may not be a key contributor
Department of Critical Care, Medicover Hospital, Hyderabad, Telangana, India

Corresponding Author: Ganshyam Jagathkar, Department of Critical Care, Medicover Hospital, Hyderabad, Telangana, India, e-mail: drganshyam@gmail.com

How to cite this article: Jagathkar G. Acute Respiratory Distress Syndrome in the Elderly. Indian J Crit Care Med 2021;25(6):613-614.

Source of support: Nil

Conflict of interest: None

toward influencing the mortality in these patients. Whether agerelated differences in resolution and repair of organ function determine the outcomes was not addressed in this study. Instead of an overwhelming immune response as a cause of mortality, the data make us look at other factors such as frailty and poor physiological reserve which can tilt significantly downward under an acute condition in these patient groups.

Does age have a direct impact on the outcomes of elderly patients with ARDS? Should age alone be the deciding factor in denying invasive mechanical ventilation to the elderly? The authors Aggarwal et al. in their study have tried to address these important issues. ${ }^{8}$ In their study, the elderly had a higher incidence of pulmonary ARDS compared to the younger population. Though the mortality in the elderly population was significantly higher than the younger patients, age in itself did not seem to be the major factor influencing the outcomes. There was no difference in the respiratory mechanics nor the gas exchange among the two groups. The ICU, as well as the hospital length of stay, was similar in both the groups, contrary to the belief that the elderly with a higher degree of frailty would have a higher length of stay. The multivariate logistic analysis suggested a higher baseline SOFA, pulmonary ARDS, and development of new organ failures as predominant factors influencing the mortality in elderly patients diagnosed with ARDS. A study by Koutsoukou et al. ${ }^{9}$ who looked at the respiratory mechanics and outcomes of elderly patients with ARDS found similar results in terms of comparable mechanics but higher mortality in the elderly group; however, they reported a significantly longer ICU length of stay compared to the younger ARDS. 
Age-dependent treatment strategies proving benefit in ARDS are lacking. Data suggest a higher incidence of ventilation-induced lung injury, probably because of the changes within the respiratory system. Lower tidal volume ventilation along with a conservative fluid strategy has been shown to be associated with positive outcomes $;{ }^{10}$ however, this is poorly adhered to among clinicians. ${ }^{11}$ Treatment options specific to the elderly need to be evolved, if we have to reduce the mortality in these patients. Considering, the underlying immune-aging and senescence of host cell, probable cell-based therapies - mesenchymal stem cell, T-regs, endothelial progenitor cell, etc.- - offer an area of research and investigation.

Finally, one also needs to look at the postdischarge quality of life as ARDS survivors are known to have significant functional disabilities. The Canadian Critical Care ${ }^{12}$ group documented several physical and psychological sequelae in ARDS survivors 5 years postdischarge. Though the lung function returned to near-normal levels, a large number of patients and their caregivers had persistence of physical and psychological issues. The older patients had a higher incidence of functional disability compared to the younger. The overall burden on resource utilization and cost was also significantly increased.

Cognitive dysfunction seems to be particularly devastating sequelae in these patients and their families and was found to be in $70-100 \%$ patients at discharge and about $20 \%$ at 5 years. ${ }^{13}$ Though cognitive impairment was reported across all groups of patients, those with a preexisting cognitive impairment may be particularly prone to severe disability. As it is common for the elderly population to have preexisting neurocognitive dysfunction, they are at very high risk for severe disabilities post-ARDS discharge.

In conclusion, as the population of the elderly is increasing, we may see more and more aged patients landing upon the ventilator for severe ARDS. Though studies have shown increased mortality in the elderly ARDS patients, this does not seem to be directly influenced by age per se, suggesting that age alone should not be the deciding factor in denying mechanical ventilation to the elderly. However, one should also look at the economic impact and the quality of life for these patients post-ICU discharge especially in a country like India where rehabilitation services are not widely available.

\section{OrCID}

Ganshyam Jagathkar @ https://orcid.org/0000-0001-9116-2096

\section{References}

1. Schouten LRA, Bos LDJ, Serpa Neto A, van Vught LA, Wiewel MA, Hoogendijk AJ, et al. Increased mortality in elderly patients with acute respiratory distress syndrome is not explained by host response. Intensive Care Med Exp 2019;7:58. DOI: 10.1186/s40635019-0270-1.

2. Suchyta MR, Clemmer TP, Elliott CG, Orme JF, Morris AH, Jacobson $J$, et al. Increased mortality of older patients with acute respiratory distress syndrome. Chest 1997;111(5):1334-1339. DOI: 10.1378/ chest.111.5.1334.

3. Villar J, Ambrós A, Soler JA, Martínez D, Ferrando C, Solano R, et al. Age, PaO2/FIO2, and plateau pressure score. Crit Care Med 2016;44(7):1361-1369. DOI: 10.1097/CCM.0000000000001653.

4. Song M, Liu Y, Lu Z, Luo H, Peng H, Chen P. Prognostic factors for ARDS: clinical, physiological and atypical immunodeficiency. BMC Pulm Med 2020;20(1):102. DOI: 10.1186/s12890-020-1131-0.

5. Luo L, Shaver CM, Zhao Z, Koyama T, Calfee CS, Bastarache JA, et al. Clinical predictors of hospital mortality differ between direct and indirect ARDS. Chest 2017;151(4):755-763. DOI: 10.1016/j. chest.2016.09.004.

6. Brody J, Thurlbeck W. Development, growth, and aging of the lung. In: Fishman A, Macklem P, Mead J, editors. Handbook of physiology, the respiratory system. Bethesda, Maryland: American Physiological Society; 1986. p. 355-386.

7. Schouten LR, van Kaam AH, Kohse F, Veltkamp F, Bos LD, de Beer FM, et al. Age-dependent differences in pulmonary host responses in ARDS: a prospective observational cohort study. Ann Intensive Care 2019;9:55. DOI: 10.1186/s13613-019-0529-4.

8. Sehgal IS, Agarwal R, Dhooria S, Prasad KT, Muthu V, Aggarwal AN. Etiology and Outcomes of ARDS in the Elderly Population in an Intensive Care Unit in North India. Indian J Crit Care Med 2021;25(6):648-654.

9. Koutsoukou A, Katsiari M, Orfanos S, Rovina N, Dimitrakopoulou C, Kotanidou A, et al. ARDS in aged patients respiratory system mechanics and outcome. Health Sci J 2017;11:2. DOI: 10.21767/1791809X.1000498.

10. Herbert JA, Valentine MS, Saravanan N, Schneck MB, Pidaparti $R_{\text {, }}$ Fowler AA, et al. Conservative fluid management prevents ageassociated ventilator induced mortality. Exp Gerontol 2016;81:101109. DOI: 10.1016/j.exger.2016.05.005.

11. Nadeem RN, Elhoufi AM, Soliman MA, Bon I, Obaida ZA, Hussien $M M$, et al. Clinical predictors of adherence to low tidal volume ventilation practice: is it different on weekend and night shifts? Cureus 2019;11(6):e4844. DOI: 10.7759/cureus.4844.

12. Herridge MS, Tansey CM, Matte A, Tomlinson G, Diaz-Granados N, Cooper $\mathrm{A}$, et al. Functional disability 5 years after acute respiratory distress syndrome. N Engl J Med 2011;364(14):1293-1304. DOI: 10.1056/NEJMoa1011802.

13. Wilcox ME, Brummel NE, Archer K, Ely EW, Jackson JC, Hopkins RO. Cognitive dysfunction in ICU patients: risk factors, predictors, and rehabilitation interventions. Crit Care Med 2013;41(9 Suppl. 1):S81S98. DOI: 10.1097/CCM.0b013e3182a16946. 